\title{
ENTRE A FILOSOFIA JURÍDICA E A SAÚDE COLETIVA: $O$ CONCEITO DE DESEMPENHO NO DECRETO N. 7.508/2011 VIS-À-VIS A INTEGRALIDADE DA ASSISTÊNCIA À LUZ DO PÓS-POSITIVISMO
}

Between legal philosophy and public health: The performance's concept in Brazilian Decree 7508/2011 vis-à-vis the comprehensive care, under the postpositivism headlight

${ }^{1}$ Universidade de São Paulo. São Paulo/SP, Brasil.

${ }^{2}$ Universidade Metodista de Piracicaba. Piracicaba/SP, Brasil.

Correspondência: Leonardo Carnut. E-mail: leonardo.carnut@upe.br.

Recebido: 11/08/2016. Revisado: 04/10/2016. Aprovado: 31/10/2016. 


\section{RESUMO}

O objetivo deste estudo foi analisar a noção de desempenho apresentada pelo Decreto n. 7.508/2011 e suas aproximações com o paradigma gerencialista da administração pública diante da integralidade da assistência. Metodologicamente, utilizou-se o Decreto n. 7.508/2011 como documento normativo para análise crítica e interpretação sob uma óptica pós-positivista, especialmente nos parágrafos relacionados ao desempenho. Após a análise, foi possível elucidar argumentos latentes ao texto de lei que demonstram o caráter gerencialista do desempenho, com diversas repercussões interpretativas para a compreensão sobre o direito ao acesso, especificamente no que tange à integralidade da assistência nos sistemas regionais de saúde. Concluiu-se que o desempenho gerencialista presente no decreto analisado, ao ser interpretado sob a luz do pós-positivismo jurídico, ao invés de fomentar a efetividade do direito à saúde via política pública, proporciona o cerceamento do acesso ao sistema pela prestação direta.

\section{Palavras-Chave:}

Avaliação em Saúde; Direito Sanitário; Legislação Sanitária; Lei Orgânica; Sistema Único de Saúde.

\section{ABSTRACT}

The aim of this study was analyze the performance notion presented by Decree 7,508/2011 and its relationship to the managerialism in public administration in dialogue with comprehensive care. Methodologically, it was used the Decree 7,508/2011 as normative document for review and interpretation in a post-positivist perspective, especially in the paragraphs related to performance. After analysis, it was possible to elucidate latent arguments to the legal text that demonstrate the managerialism character of the performance idea with several interpretative implications for the understanding of the right to access, specifically with regard to comprehensive care in regional health systems. It was concluded that the managerialist performance in this decree, when it was interpreted by postpositivism approach, instead of promoting the effectiveness of the right to health through public policy, provides the restriction of access to the system for the direct provision.

\section{Keywords:}

Brazilian National Public Health System; Health Evaluation; Health Law; Health Evaluation; Organic Law. 


\section{Introdução}

Em que pese a relevante tarefa de ordenar juridicamente os sistemas regionais de saúde, as principais críticas ao Decreto n. $7.508 / 2011^{1}$ repousam na capacidade de limitar a interpretação do "atendimento integral", pretendida na Constituição Federal de $1988(\mathrm{CF} / 88)^{2}$, e na competitividade que a noção de desempenho sugere. Logo, esperar uma hermenêutica ampliada em um Judiciário frequentemente dogmático pode gerar intepretações do decreto que não ajudem a efetividade do direito à saúde.

Sob uma análise pós-positivista, é possível identificar a inspiração gerencialista que está escamoteada na letra da lei. Assim, a noção de desempenho que pertence a essa ideologia de gestão ameaça a lógica de "sistema" pretendida por uma configuração regional conforme o decreto dispõe. Por isso, analisá-lo sob uma óptica pós-positivista é uma tentativa de recuperar a ideia de justiça sanitária orginalmente desejada ao direito à saúde no texto constitucional.

Analisando-se os valores e os princípios que regem o direito à saúde de acordo com o que preconiza a interpretação pós-positivista, entende-se como valor máximo a dignidade da pessoa humana e como princípio fundamental a integralidade da assistência (na qual o decreto reafirma a "região" como unidade geopolítica para seu alcance). Sem a exequibilidade desses dois elementos em sua possibilidade mais ampliada, estar-se-ia, por óbice interpretativo, desmontando seu núcleo essencial e, por consequência, ferindo a efetividade desse direito.

Ante o exposto, este artigo focou a análise da noção de desempenho apresentada pelo Decreto n. 7.508/2011 sob um olhar pós-positivista deste instrumento legal. Admitiu-se que essa noção apresenta forte conotação gerencialista, podendo cercear o direito à saúde no âmbito de sua interpretação/operacionalização e indo de encontro aos cânones da filosofia jurídica e da própria saúde coletiva.

\section{A interpretação pós-positivista do dispositivo legal}

\section{Pela filosofia jurídica}

O direito à saúde é um direito fundamental; portanto, está vinculado aos três poderes (Legislativos, Executivo e Judiciário) e não pode ser subtraído - nem mesmo

\footnotetext{
${ }^{1}$ BRASIL. Decreto n. 7.508, de 28 de junho de 2011. Regulamenta a Lei n 8.080, de 19 de setembro de 1990, para dispor sobre a organização do Sistema Único de Saúde - SUS, o planejamento da saúde, a assistência à saúde e a articulação interfederativa, e dá outras providências. Disponível em: <http://www. planalto.gov. br/ccivil_03/_ato2011-2014/2011/decreto/d7508.htm>. Acesso em: 31 maio 2017.

2“Art. 198. As ações e serviços públicos de saúde integram uma rede regionalizada e hierarquizada e constituem um sistema único, organizado de acordo com as seguintes diretrizes: [...] II - atendimento integral, com prioridade para as atividades preventivas, sem prejuízo dos serviços assistenciais;" BRASIL. Constituição da República Federativa do Brasil de 1988. Disponível em: <http://www.planalto.gov.br/ ccivil_03/constituicao/constituicaocompilado.htm>. Acesso em: 31 maio 2017.
} 
sob emenda constitucional. $\mathrm{O}$ fato de ser um direito fundamental implica dizer também que, no exercício desses poderes e dentro do limite da realidade, o Estado está obrigado a promover a saúde na maior medida do possível. Nesse sentido, os poderes públicos devem realizar todos os esforços para efetivar esse direito, pois sua concretude só ocorrerá quando tudo aquilo que for fática e juridicamente possível seja feito 3 .

No caso do Decreto n. 7.508/2011, a restrição do direito ao acesso aos serviços de saúde aconteceu ditatorialmente. Em nenhum momento essa normativa foi apreciada por um conjunto legislativo que julgasse sua viabilidade técnica, sua técnica legislativa e muito menos sua constitucionalidade no que se refere à constrição do significado de integralidade da assistência.

Assim, é importante ressaltar que a fixação constitucional pétrea do direito à saúde (compreendida como direito social) tem como prerrogativa que a natureza dessa regra não é passível de mudança por ordem do Executivo, já que o direito à saúde faz parte do poder constituinte derivado, cabendo apenas ao Legislativo, após ampla discussão com a sociedade civil, determinar mudanças na própria interpretação/operacionalização no princípio desse direito.

Mesmo assim, certos autores ${ }^{4}$ defendem a ideia de que contornos jurídicos mais rígidos ao direito à saúde devem existir tanto em relação às condições que evitem doenças (qualidade de vida) quanto na definição de um "padrão de integralidade", e não da integralidade da assistência em seu sentido original, dos serviços de saúde - ou seja: quais serviços de saúde o Estado garantirá? Dessa maneira, entende-se por "padrão de integralidade" uma escolha que a sociedade e o poder público devem fazer, conjuntamente, em relação aos serviços de saúde que vão compor o rol de serviços que o Sistema Único de Saúde (SUS) garantirá à sociedade como um todo.

Esse é um caso clássico de problema de validade da norma jurídica, sobre o qual o Decreto n. 7.508/2011 se assenta. Somente pode ser considerada como integrante do sistema jurídico a norma que observar requisitos de competência, de forma e de conteúdo - requisitos materiais relacionados com seu objeto. Há que ser exarada por autoridade competente, na forma legal, e seu objeto juridicamente válido, ou seja, a finalidade da norma jurídica deve ser sempre voltada ao interesse público.

Podemos dizer assim que as normas jurídicas possuem limitações materiais (de conteúdo), formais (de procedimentos) e de competência. Especialmente em relação à fonte da norma, a validade da mesma depende da competência do órgão

${ }^{3}$ RIOS, Roger Raupp. 0 direito fundamental à saúde e atividade legislativa. In: ALVES, Sandra Mara Campos; DELDUQUE, Maria Célia; DINO Neto, Nicolao. Direito Sanitário em perspectiva. Brasília: ESMPU: Fiocruz, 2013. v. 2, p. 169-180.

${ }^{4}$ SANTOS, Lenir. Direito a saúde e qualidade de vida - um mundo de corresponsabilidades e fazeres. In: (Org.). Direito da saúde no Brasil. Campinas, SP: Saberes Ed., 2010. p. 15-64. 
que a editou, devendo-se sempre verificar se tal órgão era legalmente competente. Em outras palavras, somente o Congresso Nacional pode aprovar um decreto legislativo e somente o Poder Executivo, um decreto regulamentar ${ }^{5}$. Contudo, em se tratando de direitos fundamentais, como é o caso do direito à saúde, a discussão no ambiente legislativo se faz compulsória.

Mesmo não sendo competente para edição do Decreto n. 7.508/2011, o Executivo o promulgou. Os argumentos manifestos residiram no fato de que a gestão pública desses sistemas de saúde, por se situarem em uma escala geográfica regional, não contava com um corpo administrativo público de uma esfera federada própria para tal $^{6}$ - remetendo-se a mais um dos inúmeros problemas do federalismo brasileiro $^{7}$, já que o constitucionalismo brasileiro não conseguiu engendrar relações intergovernamentais de cooperação e de controle mútuo ${ }^{8}$.

Nasce aí a discussão acerca da segurança jurídica nas relações interfederativas e toda a problemática relacionada à articulação intergovernamental. O decreto tenta resolver esse problema com a criação do Contrato Organizativo da Ação Pública da Saúde (COAP).

Já o outro argumento afirma a necessidade de mais transparência na gestão do SUS para a promoção de um maior controle social ${ }^{9}$. Nesse caso, a forma de resolução seria a fixação de responsabilidades claras na competência de cada esfera de gestão do sistema regional e a condução da avaliação do desempenho nos moldes da new public management.

Contudo, o argumento latente - e que, de longe, foi largamente discutido - foi tratado na constrição jurídica do sentido de integralidade da assistência. Com enfoque em uma realidade prática, o direito à saúde encontra-se sempre e de algum modo afetado pela assim designada reserva do financeiramente possível, em suas diversas manifestações, seja pela disponibilidade de recursos existentes, que abrange também a própria estrutura organizacional e a disponibilidade de tecnologias

${ }^{5}$ AITH, Fernando. Curso de direito sanitário: a proteção do direito à saúde no Brasil. São Paulo: Quartier Latin, 2007. p. 405.

${ }^{6}$ BRASIL. Ministério da Saúde. PROADESS - Avaliação de Desempenho do Sistema de Saúde brasileiro: indicadores para monitoramento. Relatório final (versão para discussão) Laboratório de Informações em Saúde - LIS Instituto de Comunicação e Informação em Ciência e Tecnologia - ICICT. Fundação Oswaldo Cruz, Rio de Janeiro, 2011.

${ }^{7}$ SOUZA, Célia. Instituições e mudanças: reformas da Constituição de 1988, federalismo e políticas públicas. In: HOCHMAN, Gilberto; FARIA, Carlos Alberto Pimenta. Federalismo e políticas públicas no Brasil. Rio de Janeiro: Fiocruz. 2013. p. 91-120.

${ }^{8}$ ROMERO, Luiz Carlos. Federalismo e responsabilidade sanitária (percalços da construção de um sistema único de saúde em um estado federado). In: ROMERO, Luiz Carlos; DELDUQUE, Maria Célia. Estudos de direito sanitário: a produção normativa da saúde. Brasília: Senado Federal: Subsecretaria de edições técnicas, 2011. p. 83-98.

${ }^{9}$ BRASIL. Ministério da Saúde. Secretaria de Gestão Estratégica e Participativa. Decreto $n^{\circ} 7.508$, de 28 de junho de 2001: regulamentação da Lei n 8.080/90 / Ministério da Saúde. Secretaria de Gestão Estratégica e Participativa. - Brasília: Ministério da Saúde, 2011. - (Série E. Legislação de Saúde). 
eficientes, seja pela capacidade jurídica (e técnica) de se dispor deles ${ }^{10}$. Nesse sentido, a escolha pelo enxugamento do sentido constitucional dado à integralidade da assistência foi a opção do membro do Executivo na ocasião.

A cláusula da "reserva do possível" versa sobre a obrigação do poder público de garantir prestações universais e integrais dentro de uma capacidade econômica e financeira do Estado para suportar os respectivos ônus. No caso da saúde, em especial, coloca-se sob avaliação a existência de condições para o Estado assumir a integralidade da assistência, inclusive farmacêutica, diante dos limites orçamentários. Não se discute, nesse campo, a existência do direito, e sim sua exigibilidade diante da finitude dos recursos. Incidiria, nesse particular, a cláusula da reserva do possível, que desobrigaria o poder público de atender pretensões que superem suas possibilidades ${ }^{11}$. Assim, a limitação do orçamento seria uma reserva material que se colocaria em face da previsão normativa do direito a uma prestação. O Estado seria eximido do dever de cumprir algumas prestações - compreendidas no conteúdo do direito social - por impossibilidade material.

Entretanto, três argumentos se contrapõem a essa condição. O primeiro é de ordem jusfilosófica: a proteção positiva do mínimo existencial não se encontra sob a reserva do possível, pois sua fruição não depende do orçamento nem de políticas públicas, ao contrário do que acontece com os direitos sociais. Em outras palavras, o Judiciário pode determinar a entrega das prestações positivas, eis que tais direitos fundamentais não dependem da discricionariedade da Administração Pública ou do Legislativo e sim estão compreendidos nas garantias institucionais da liberdade, na estrutura dos serviços públicos essenciais e na organização de estabelecimentos públicos (hospitais, clínicas, escolas primárias etc.) ${ }^{12}$.

O segundo argumento é de ordem semântico-conceitual. A vinculação entre provisão mínima e necessidade básica tem conduzido a uma crescente tendência de se identificar semanticamente "mínimo" com o "básico" e, por consequência, equipará-los no plano político-decisório, o que constitui uma temeridade. "Mínimo" e "básico" são conceitos distintos, pois, enquanto o primeiro tem a conotação de "menor", de "menos" em sua concepção ínfima, identificada com patamares de satisfação de necessidades que beiram a desproteção social, o segundo não. O "básico"

\footnotetext{
${ }^{10}$ SARLET, Ingo Wolfgang; FIGUEIREDO, Mariana Filchtiner. Reserva do possível, mínimo existencial e direito à saúde: algumas aproximações. Revista da Defensoria Pública, v. 1, n. 1, p. 179-234, jul./dez. 2008. Disponível em: <https://www.defensoria.sp.def.br/dpesp/repositorio/20/publicacoes/Revista_1_ volume_2.pdf>.

${ }^{11}$ WEICHERT, Marlon Alberto. $O$ direito à saúde e o princípio da integralidade. In: SANTOS, Lenir (Org.). Direito da Saúde no Brasil. Campinas, SP: Saberes Ed., 2010. p. 101-142.

${ }^{12}$ TORRES, Ricardo Lobo. O direito à saúde, o mínimo existencial e a Defensoria Pública. Revista da Defensoria Pública, v. 1, n. 1, p. 265-278, jul./dez. 2008. Disponível em: <https://www.defensoria.sp.def.br/dpesp/ repositorio/20/publicacoes/Revista_1_volume_2.pdf>.
} 
expressa algo fundamental, principal, primordial, que serve de base de sustentação indispensável e fecunda ao que a ele se acrescenta ${ }^{13}$.

Portanto, o básico constitui pré-requisito ou condições prévias para o exercício da cidadania em sua acepção mais larga; o mínimo, contudo, pressupõe supressão ou cortes de atendimento, tal como propõe a ideologia neoliberal. O básico requer investimentos sociais de qualidade para preparar o terreno a partir do qual maiores atendimentos podem ser prestados e otimizados. Em outros termos, enquanto o mínimo nega o "ótimo" de atendimento, o básico é a mola mestra que impulsiona a satisfação básica das necessidades em direção ao ótimo.

Os enunciados normativos que versam sobre vida e saúde (e.g., o artigo 196 da $\mathrm{CF} / 88$ ) buscam proteger e promover um bem da vida, o que não convive facilmente com gradações ${ }^{14}$. Não há alguma coisa que possa ser descrita com simplicidade como um nível mínimo de saúde ou ainda um mínimo de vida. Afinal, é dizer que saúde é um bem jurídico relacionado de forma indissociável com o maior bem jurídico que existe: a vida ${ }^{15}$. Tendo a vida como guia, ou se faz um determinado tratamento e se obtém a cura, ou o indivíduo permanecerá doente ou morrerá. Nessa esteira, o que seria o mínimo para o portador de leucemia em um estágio tal que a única prestação que lhe pode trazer alguma esperança é o transplante de medula? Ou para alguém com câncer? Em um contexto de recursos escassos, como o direito pretende lidar com essa circunstância?

Por fim, o terceiro argumento, como não poderia deixar de ser, é de ordem econômico-financeira. As duas instituições brasileiras mais respeitadas e que vêm realizando análises robustas sobre a estrutura orçamentária da seguridade social a Associação Nacional dos Auditores Fiscais da Receita Federal do Brasil (ANFIP) e o Instituto de Pesquisa Econômica Aplicada (Ipea) -, mesmo utilizando metodologias diferenciadas de análise, afirmam que a seguridade social é superavitária é que possível não somente cobrir as despesas das três políticas públicas (dentre as quais está a saúde), mas, sobretudo, ampliá-las, sendo seu principal impeditivo a Desvinculação das Receitas da União (DRU) e sua destinação ao superávit primário ${ }^{16}$.

Nesse sentido, o amparo ao princípio da integralidade da assistência está razoavelmente justificado juridicamente. Afinal, quando se trata da discussão sobre

\footnotetext{
${ }^{13}$ PEREIRA, Potyara Amazoneida Pereira. Do mínimo ao ótimo de satisfação das necessidades mediante o conceito de básicos sociais. In: . Necessidades humanas: subsídios à crítica dos mínimos sociais. 5a. Edição. São Paulo: Cortez, 2008. p. 23-36.

${ }^{14}$ BARCELLOS, Ana Paula de. O direito a prestações de saúde: complexidades, mínimo existencial e o valor das abordagens coletiva e abstrata. Revista da Defensoria Pública, v. 1, n. 1, p. 133-160, jul./dez. 2008. Disponível em: <https://www.defensoria.sp.def.br/dpesp/repositorio/20/publicacoes/Revista_1_volume_2.pdf>.

${ }^{15} \mathrm{VIAL}$, Sanda Regina Martini; OLIVEIRA, Christiano Augusto Seckler. O direito à saúde e os determinantes sociais. Revista da Defensoria Pública, v. 1, n. 1, p. 279-292, jul./dez. 2008. Disponível em: <https://www. defensoria.sp.def.br/dpesp/repositorio/20/publicacoes/Revista_1_volume_2.pdf>.

${ }^{16}$ MARTINIANO, Claudia et al. A luta pela vinculação de recursos para a saúde pública no Brasil a partir do paradigma da universalização. In: DAVI, Jordeana; MARTINIANO, Claudia; PATRIOTA, Lucia Maria. Seguridade social e saúde: desafios e tendências. 2. ed. Campina Grande: Eduepb. 2011. p. 85-116.
} 
a integralidade, não se deve buscar um conceito específico e fechado, mas sim alguns sentidos que se refiram às práticas concretas em saúde que buscam a atenção integral, pois a integralidade é mais um processo de construção social do que métodos e técnicas bem elaborados (inclusive jurídicos). Nessa perspectiva, a integralidade implica, necessariamente, uma recusa ao reducionismo, à objetivação dos sujeitos ${ }^{17}$.

\section{Pela saúde coletiva}

$\mathrm{Na}$ esfera política, um grande desafio do SUS e da operacionalização do direito à saúde é o modelo a ser adotado para a prestação dos serviços. Embora a Lei n. 8.080/1990 (Lei Orgânica da Saúde - LOS) seja clara ao afirmar que o SUS deve ser composto de ações e serviços prestados pela administração direta ou indireta da União, dos estados, do Distrito Federal e dos municípios, há um grande movimento nacional de terceirização dos serviços públicos de saúde. A justificativa para essa tendência é a de que é impossível prestar serviços públicos de saúde com qualidade/eficiência dentro das rígidas estruturas da administração pública, sendo a terceirização o melhor caminho para um serviço célere, mesmo sob as assimetrias entre governos subnacionais ${ }^{19}$. Contudo, não é esse o sentido da CF/88 nem da LOS. Nesses textos normativos, vê-se claramente que os serviços públicos de saúde devem ser prestados pela administração pública, e não por terceiros privados.

No entanto, carregados de componentes ideológicos, os modelos de prestação de serviços de saúde no Brasil são, em última instância, definidos pelo direito (em especial pelo Direito Administrativo) que, após a reforma administrativa do estado conduzida por Bresser-Pereira, passou a ter uma gama ampla de opções. Como reforçado por Maria Sylvia Zanella di Pietro ${ }^{20}$ : "o que muda é principalmente a ideologia, é a forma de conceber o Estado e a Administração Pública”. Não se quer mais o Estado prestador de serviços; quer-se o Estado que estimula, que ajuda e que subsidia a iniciativa privada.

Logo, é fundamental compreender que o apelo a tais modelos alternativos para prestação em saúde é, na melhor das hipóteses, uma forma de mascaramento do abuso do poder econômico no setor, com implicações práticas para a efetivação do

${ }^{17}$ SIQUEIRA, Márcia Portugal; BUSSINGUER, Elda Coelho de Azevedo. A saúde no Brasil enquanto direito de cidadania: uma dimensão da integralidade regulada. Revista de Direitos e Garantias Fundamentais, v. 8, p. 253-309, 2010. Disponível em: <http://sisbib.fdv.br/index.php/direitosegarantias/article/view/37/35>. http://dx.doi.org/10.18759/rdgf.v0i8.37.

${ }^{18}$ BRASIL. Lei n. 8.080, de 19 de setembro de 1990. Dispõe sobre as condições para a promoção, proteção e recuperação da saúde, a organização e o funcionamento dos serviços correspondentes e dá outras providências. Disponível em: <http://www.planalto.gov.br/ccivil_03/leis/L8080.htm>. Acesso em: 31 maio 2017.

${ }^{19}$ LIMA, Luciana Dias. Federalismo, descentralização e regionalização na política de saúde do Brasil. In: ASENSI, Felipe Dutra; PINHEIRO, Roseni (Orgs.). Direito sanitário. Rio de Janeiro: Elsevier. 2012. p. 131-161.

${ }^{20}$ DI PIETRO, Maria Sylvia Zanella. Introdução. In: Parcerias na administração pública: concessão, permissão, franquia, terceirização e outras formas. 4. Edição. São Paulo: Atlas, 2002. p. 16. 
direito à saúde, em especial na destituição de seu caráter público ${ }^{21}$. Assim, apoiar-se no baralhamento entre o público e o privado (marca da sociedade, do Estado e da cultura política brasileira desde a colonização) constitui uma das construções intelectuais mais recorrentes no pensamento social brasileiro ${ }^{22}$ e, obviamente, um reforço à cultura da privatização.

Nessa esteira, a economia, agora em escala globalizada, vem conformando e submetendo os Estados nacionais a suas regras de maximização e acumulação de superlucros ${ }^{23}$. A perspectiva do ajuste estrutural do Estado, a chamada "reforma do estado", funda-se na necessidade do capital de "liberalizar" - desimpedir, desregulamentar - os mercados e, assim, conceber-se como parte do desmonte das bases de regulação das relações sociais, políticas e econômicas.

Portanto, para tal reforma, é claro que não se trata de um “ajuste positivo" de caráter meramente administrativo-institucional, restrito ao plano político-burocrático, mas sim, de uma mudança articulada à reestruturação produtiva, à retomada das elevadas taxas de lucro, à ampliação da hegemonia político-ideológica do grande capital. Dessa maneira, é pertinente registrar que o Decreto n. 7.508/2011 foi elaborado em um ambiente cujo caráter político, econômico e ideológico visa a alterar as bases da tentativa de um estado de bem-estar social construídas no interior de um pacto socialdemocrata. Assim, o tempo sociohistórico vigente foi o de desmonte de diversas conquistas sociais trabalhistas, políticas e econômicas desenvolvidas ao longo do século XX - no lugar de uma reforma, constituiu-se uma verdadeira contrarreforma do Estado ${ }^{24}$.

Como afirmam alguns autores ${ }^{25}$, para a teoria neoliberal não é o capitalismo que está em crise, mas o Estado. A estratégia, portanto, é reformar o Estado ou diminuir sua atuação para superar a crise. O mercado é que deverá superar as falhas do Estado, portanto, a lógica do mercado deve prevalecer - inclusive no Estado, para que este possa ser mais "eficiente" e "produtivo". Por isso, caracterizar a crise do estado de bem-estar social no Brasil como uma "crise fiscal", "crise de governança", ou ainda, uma "crise no modo de administração estatal" torna-se o elemento simbólico necessário para que a teoria neoliberal se fortaleça.

\footnotetext{
${ }^{21}$ SANTOS, Nelson Rodrigues. A regulamentação da emenda constitucional n. 29: dificuldades e perspectivas. In: ROMERO, Luiz Carlos; DELDUQUE, Maria Célia. Estudos de direito sanitário: a produção normativa da saúde. Brasília: Senado Federal: Subsecretaria de edições técnicas, 2011. p. 73-82.

${ }^{22}$ BOTELHO, André. O público e o privado no pensamento social brasileiro. In: BOTELHO, André; SCHWARCZ, Lilia Moritz (Orgs.). Cidadania, um projeto em construção. São Paulo: Claro Enigma, 2012, p. 48-59.

${ }^{23}$ LAURELL, Asa Cristina. Avançando em direção ao passado: a política social no neoliberalismo. In: Estado e políticas sociais no neoliberalismo. 3. ed. São Paulo: Cortez, 2002. p. 151-178.

${ }^{24}$ MONTAÑO, Carlos; DURIGUETTO, Maria Lúcia. A (contra)reforma do Estado no Regime de Acumulação Flexível (pós-1973). In: Estado, classe e movimento social. 3. ed. São Paulo: Cortez, 2011. p. 180-224.

${ }^{25}$ PERONI, Vera Maria Vidal. Políticas sociais em tempos de redefinições do papel do Estado. In: GUIMARÃES, Geny Terezinha Duro; EIDELWEIN, Keren. As políticas sociais brasileiras e as organizações financeiras internacionais. Porto Alegre: Edipucrs, 2010. p. 95-114.
} 
A aparente polêmica sobre a reforma do Estado se pauta na ideia de ineficiência estatal - como se fosse inexorável -, travestida de tecnicismo, já que a crise nunca é entendida como uma crise orgânica do capital. A crise passa a ser centrada apenas em um modelo de Estado; caso esse modelo - e consequentemente sua forma de administração - mude, resolverá a situação da crise instalada ${ }^{26}$. Para isso, foi proposto um modelo gerencial para dar conta das exigências de efetividade e eficiência. Houve o redesenho da organização estatal, com a redistribuição de suas funções entre novos organismos não estatais. A principal inovação é a criação de uma esfera pública não estatal, que, embora exercendo funções públicas, obedece claramente a leis de mercado ${ }^{27}$.

Assim, essa crise, claramente associada à crise capitalista de superprodução e superacumulação, é mais um desdobramento da crise estrutural do capitalismo. Nesse bojo, a contrarreforma, caracterizada pelo desmonte do sistema de proteção social, teve seu início na década de 1970 na Europa, em virtude de mais uma crise sistêmica do capital. A luta por ganhos de produtividade fez como que o grande capital diminuísse progressivamente a manutenção dos fundos sociais públicos, afetando sobremaneira o financiamento das políticas sociais em curso $^{28}$. Fica claro que, sob essa análise, o encaminhamento seria o Estado abrir mão de sua responsabilidade para com as políticas sociais.

A distância entre a imposição de uma política pública de saúde de cunho universalista e as pressões, sempre maiores, por uma contrarreforma do Estado que atenda as exigências da política governamental de orientação neoliberal e minimize custos como princípio norteador ${ }^{29}$ desresponsabilizam o Estado para com o direito prestacional à saúde. É pertinente lembrar que, segundo o disposto no artigo 199 da $\mathrm{CF} / 88$, "a assistência à saúde [entendida como a relação prestacional restrita ao contato direto entre o profissional de saúde e o paciente] é livre à iniciativa privada" (destaques nossos), mantendo a responsabilidade exclusiva do Estado pela gestão do sistema público, não sendo, portanto, constitucionalmente passível de concessão/delegação/terceirização ou quaisquer outros léxicos que se assemelhem semanticamente para entes privados.

\footnotetext{
${ }^{26}$ BRAVO, Maria Inês Souza; MATOS, Maurílio Castro de. A saúde no Brasil: reforma sanitária e a ofensiva neoliberal. In: BRAVO, Maria Inês Souza; PEREIRA, Potyara Amazoneida Pereyra. Política social e democracia. São Paulo: Cortez; Rio de Janeiro: UERJ, 2012, p. 200-220.

${ }^{27}$ BRAVO, Maria Inês Souza. Considerações finais. In: fundamentos sócio-históricos. São Paulo: Cortez, 2013. p. 169-180.

${ }^{28}$ SILVA, Maria Magdala Vasconcelos de Araújo. Capitalismo e políticas sociais: o dilema da autonomia dos cidadãos e da defesa da universalidade dos direitos sociais. In: PASTORINI, Alejandra; ALVES, Andrea Moraes; GALIZIA, Silvina Veronica. Estado e cidadania: reflexões sobre as política públicas no Brasil contemporâneo. Rio de Janeiro: Ed. FGV, 2012. p. 17-44.

${ }^{29}$ MINAYO, Maria Cecilia de Souza. Sobre a complexidade de implementação do SUS: In: SILVA, Silvio Fernandes da (Org). Municipalização da saúde e poder local: sujeitos, atores e políticas. São Paulo: Hucitec, 2001. p. 21-44.
} 
Quando o Estado não se responsabiliza sanitariamente por seu sistema regional de saúde, a integralidade da assistência sofre consequências em sua efetivação. Isso decorre por dois mecanismos diferentes, mas totalmente imbricados.

O primeiro, de caráter mais geral, repousa na dicotomia entre público e privado. As várias questões pertinentes à relação público-privado no SUS vêm configurando um "emaranhado" complexo de distorções privatizantes e escapismos da gestão pública para enfrentar o desinvestimento. A maior contradição ou conflito administrativo explícita nesse "emaranhado", em que as terceirizações, ao contrário de serem desenvolvidas como complementares ou suplementares e em situações específicas, foram alçadas para o espaço central do sistema ${ }^{30}$, é fruto do processo de "empresarialização" do sistema, das "parcerias" com os setores privado e da introdução da nova gestão pública (new public management). A tradicional regulação em termos de direito público vê-se confrontada com o desenvolvimento de uma crescente utilização do direito privado ${ }^{31}$, que invade o espaço do Direito Administrativo indo em direção ao Direito Econômico.

Assim, o gerencialismo incutido na lógica de formulação do direito ao acesso aos serviços de saúde pelo Decreto n. 7.508/2011 demonstra a capacidade de articulação de dois poderes - Executivo e Legislativo - que mina a construção da saúde como direito social e favorece a ordem econômica.

Como consequência, o direito à saúde passou a ser encarado como um problema da colisão de direitos. Sua discussão deixou de ser analisada no âmbito dos direitos fundamentais para dispersar-se em outros microssistemas jurídicos. O maior interessado, o usuário que precisa acessar o direito, deixou de ser o tutelado para se fragmentar entre o interesse dos gestores públicos, que advogam pela privatização, justificados no desinvestimento do SUS provocado pela adoção de uma política econômica neoliberal, e dos gestores privados, que administram a prestação do serviço e pretendem lucrar com uma nova segmentação da oferta por dentro - haja vista as primeiras iniciativas relacionadas à dupla porta de entrada. Esse movimento desencadeou a um ardiloso jogo lógico-interpretativo, ainda justificado equivocadamente na primazia do interesse público (gestores da coisa pública) sobre o particular (o indivíduo).

O segundo mecanismo pelo qual a integralidade da assistência se desestrutura é o alvo principal de toda a argumentação proferida até agora. Trata-se do processo de gerenciamento dos serviços públicos de saúde a partir da noção de

\footnotetext{
${ }^{30}$ SANTOS, Nelson Rodrigues. SUS, política pública de Estado: seu desenvolvimento instituído e instituinte e a busca de saídas. Ciência \& Saúde Coletiva, v. 18, n. 1, p. 273-280, 2013. Disponível em: <http://www. scielo.br/pdf/csc/v18n1/28.pdf>. http://dx.doi.org/10.1590/S1413-81232013000100028.

${ }^{31}$ LOUREIRO, João Carlos. Direito à (proteção da) saúde. Revista da Defensoria Pública, v. 1, n. 1, p. 3574, jul./dez. 2008. Disponível em: <https://www.defensoria.sp.def.br/dpesp/repositorio/20/publicacoes/ Revista_1_volume_2.pdf>.
} 
desempenho gerencialista. Em serviços de saúde, a forma de avaliação do desempenho tradicionalmente utilizada vem da teoria donabediana, segundo a qual os serviços são observados no tocante à estrutura, ao processo e aos resultados obtidos ${ }^{32}$. $\mathrm{Na}$ visão da gestão gerencialista, o foco no resultado se agudiza e se sobrepõe à ordem dos outros elementos que compõem o que o desempenho pode vir a alcançar. Assim, o desempenho gerencialista foca todo o esforço de análise da prestação no "resultado", o que já reduz a abordagem em pelo menos um terço e retira do foco o que prescinde de investimentos: a estrutura e o processo.

Por definição, é razoavelmente consensual que o desempenho esteja relacionado à expectativa de um cumprimento comportamental previamente estabelecido. O que se determina como "comportamento previamente estabelecido" em saúde, em última instância, depende da expectativa que a sociedade tem dos serviços no âmbito de sua prestação direta. Sem o intuito de percorrer o quanto a garantia da saúde extrapola o próprio setor, pois é fato que aquilo que os serviços de saúde apresentam como "resultados", donabedianamente falando, são "processos", o Decreto n. 7.508/2011, embora verse explicitamente sobre acesso a serviços de saúde, na verdade, trata do desempenho destes. O que se espera de serviços de saúde, sem grandes pretensões, é um atendimento, um serviço prestado, no sentido mais puro da palavra ${ }^{33}$.

Em sua essência, essa prestação difere da prestação de outros tipos de serviço, pois os serviços de saúde não são passíveis de padronização ${ }^{34}$; dependem de recursos humanos muito qualificados; são altamente dependentes de relações interpessoais, tais como vínculo, escuta, paciência, tolerância etc.; e ainda apresentam fragmentação organizacional, pois nem todas as organizações possuem os recursos suficientes para resolver todos os problemas de um usuário ${ }^{35}$, colocando em xeque o próprio sentido de "resolvido" e tornando o resultado (com base na expectativa que for) em um "não resolvido", na maioria das vezes.

Assim, denotar o desempenho sem levar em consideração essas características essenciais é no mínimo um acinte intelectual - prova de que o desempenho gerencialista desconfigura o que há de essencial na prestação direta do serviço de saúde, pois os resultados expressos, na maioria das vezes, são obtidos por quantificadores padronizados, não refletem o nível de qualificação do profissional para a prestação sob sua responsabilidade, não consideram a construção das relações interpessoais

\footnotetext{
${ }^{32}$ DONABEDIAN, Avedis. Aspects of medical care administration. Boston: Harvard University Press; 1973.

${ }^{33}$ MEIRELLES, Dilmária Silva e. O conceito de serviço. Revista de Economia Política, v. 26, n. 1, p. 119-136, 2006. Disponivel em: <http://www.scielo.br/pdf/rep/v26n1/a07v26n1.pdf>. http://dx.doi.org/10.1590/ S0101-31572006000100007.

${ }^{34}$ SPILLER, Eduardo Santiago; SENNA, Ana Maria; SANTOS, José Ferreira dos; VILAR, Josier Marques. Fundamentos da gestão dos serviços de saúde. In: ___ Gestão do serviços de saúde. Rio de Janeiro: Ed. FGV, 2009. p. 19-44.

${ }^{35}$ NOGUEIRA, Roberto Passos. O trabalho em serviço de saúde. In: SANTANA, José Paranaguá et al. Desenvolvimento gerencial de unidades básicas do Sistema Único de Saúde (SUS). Brasília: Programa de Desenvolvimento de Recursos Humanos; 1997. p. 183-186
} 
necessárias ao cuidado e, por fim, sequer captam o acesso aos serviços (neste último aspecto, esbarra-se mais uma vez na questão da integralidade da assistência).

Faz parte da noção de desempenho seu tratamento como sendo uma métrica - a defasagem ou superação do comportamento esperado. Daí emerge a problemática do método de mensuração como algo relevante. $\mathrm{O}$ ato de medir (quantitativa ou qualitativamente) deve se preocupar em estar de acordo conceitual com o objeto medido; do contrário, conta com o prejuízo de não captar o que se pretende. Além disso, a medição de fenômenos complexos e intangíveis (como prestações de serviços), que dependem de diversas variáveis em intrínseca conexão, ao ser reduzida a um conjunto de indicadores tende a perder em conteúdo explicativo e, por consequência, torna invisíveis atos ou processos que sejam cruciais no efeito final das prestações. Afinal, como coloca Niek Klazinga ${ }^{36}$, "o que não é medido não é feito". Nesse sentido, a perda de informações sobre como e o qu os serviços de saúde produzem em termos de prestação desinforma o que o desempenho pode ou não se tornar, haja vista que a métrica pode estar abaixo, dentro ou acima da expectativa firmada. Nessas circunstâncias, como identificar aquilo que garantiu o desempenho?

No formato gerencialista, o desempenho, além de padecer dos aspectos métricos relatados, que já apresentam características reducionistas, põe-se a serviço do desequilíbrio entre as organizações. A premiação financeira, no formato pay-for-performance, derivada do mérito "funcional" da organização e não do acesso ao serviço pelo usuário, muito menos do "resultado resolvido", fruto da lógica da superação das expectativas de comportamento, em sistemas regionais, pode criar ilhas de excelência, enquanto os demais serviços ficam à míngua. Com um caráter de competição claramente expresso, a premiação no desempenho gerencialista vislumbra o desenvolvimento de quem já se apresenta bem, com variáveis que contam mais a favor do que aqueles que apresentam atos e processos ainda descoordenados, recursos humanos despreparados e acesso restrito.

No que tange a ocasião de competição entre público-público, o avanço do desempenho em uma das duas organizações ainda permite o reinvestimento público deste incentivo financeiro no patrimônio do Estado. Já na competição entre o público-privado, a desvantagem para o público se configura mais uma vez, na qual o incentivo para o serviço privado necessariamente não se configura em reinvestimento para o patrimônio estatal. Essa última lógica ainda promove, em determinadas condições, uma hipertrofia do privado sobre o público fazendo com que o público raramente disponha de incrementos em pessoal ou de tecnologia mais sofisticada para favorecer o acesso da população.

\footnotetext{
${ }^{36}$ KLAZINGA, Niek. Health system performance management: quality for better or for worse. Eurohealth, United Kingdom, v. 16, n. 3, p. 26, 2010.
} 
Assim, o desempenho gerencialista não se propõe a atuar de acordo com o princípio filosófico do SUS - que é a equidade no acesso, com repercussões na noção de inclusão. Sob o ângulo da implementação de suas diretrizes constitucionais, o desempenho gerencialista tem dificuldades de processar a inclusão social, pois há um reforço da hegemonia do "modelo da oferta", medicalizado, privatizado e "modernizado" pelo "gerencialismo".

Nesse sentido, é inescapável identificar uma presente constância da ideologia política liberal nessa construção gerencial de redes. É possível constatar uma inflexão no pensamento burguês em relação ao debate sobre mercado e o estado de bem-estar social, na qual uma epistemologia de direita - de maximização e otimização dos recursos, escassez relativa, capital humano e capital social - é envernizada por uma ética de "esquerda", com palavras de ordem como "equidade", "justiça social" e "solidariedade" 37.

Se assim for, para a efetivação do direito à saúde é necessário que o SUS gere a promoção, proteção e recuperação da saúde dos indivíduos e das coletividades ${ }^{38}$ sob a premissa de que a universalidade, a equidade e, principalmente, a integralidade (que dependem do provimento de políticas sociais) venha antes da eficiência e da otimização (que dependem de políticas econômicas) e que assegure desenvolvimento econômico sustentável e distribuição de renda. É pertinente lembrar ainda que a organização da prestação via políticas e programas pode promover ou violar os direitos humanos em seu propósito ou implementação ${ }^{39}$.

A partir da perspectiva da ciência social e da justiça social, os três conceitos que mais têm a oferecer, embora continuem a ser subteorizados e inadequadamente operacionalizados, são: a salvaguarda da dignidade das pessoas; a promoção da equidade, ou não discriminação; e a participação dos indivíduos e grupos nas questões que os afetam ${ }^{40}$.

Logo, no Decreto n. 7.508/2011, o desempenho gerencialista traz um novo cenário para a política social, da qual a saúde faz parte como direito social, criando novas condições para a luta social em que "nem consumo coletivo, nem direitos sociais, apenas assistência focalizada para 'aqueles com menor capacidade de pressão' ${ }^{41}$ finda por se estabelecer”. Afinal, isso tudo ocorre sob a norma de que os entes

\footnotetext{
${ }^{37}$ CASTELO, Rodrigo. O social-liberalismo brasileiro e a miséria ideológica da economia do bem-estar. In: MOTA, Ana Elizabete. (Org.). Desenvolvimentismo e construção de hegemonia: crescimento econômico e reprodução da desigualdade. São Paulo: Cortez, 2012. p. 46-77.

${ }^{38}$ FIGUEIREDO NETO, Manoel Valente et al. O processo histórico de construção do Sistema Único de Saúde brasileiro e as novas perspectivas. Revista Âmbito Jurídico, v. 5, n. 10, p. 77-81, 2010. Disponível em: <http://www.ambito-juridico.com.br/site/index.php?n_link=revista_artigos_leitura\&artigo_id=7781>

${ }^{39}$ NYGREN-KRUG, Helena. Saúde e direitos humanos na Organização Mundial da Saúde. Revista de Direitos Humanos e Saúde, v. 1, n. 1, p. 13-18, 2004.

${ }^{40}$ VANDERPLAAT, Madine. Direitos Humanos: uma perspectiva para a saúde pública. Revista de Direitos Humanos e Saúde, v. 1, n. 1, p. 27-34, 2004.

${ }^{41}$ BERHING, Elaine Rossetti. Política social no capitalismo tardio. 5. ed. São Paulo: Cortez, 2011.
} 
privados sejam devidamente "controlados" pelo Estado e pela sociedade civil (no momento em que o discurso econômico é "desregular").

Assim, a crítica relativa ao desempenho gerencialista nessa normativa vem em virtude da necessidade de investigação de seus fundamentos teóricos, à luz dos direitos humanos fundamentais. Este estudo trouxe à baila os problemas para a efetivação do direto ao acesso aos serviços de saúde no cotidiano das práticas, desvendados pela interpretação pós-positivista. Por isso, compreender como o decreto compromete a efetividade desse direito ajuda a perceber como as conquistas históricas dos direitos sociais podem ser reduzidas à mera retórica hegemônico-conservadora de uma ordem global fundada na desigualdade e na exploração ${ }^{42}$.

Ante o exposto, tratar da efetividade da saúde como um direito universal é um desafio constante na ordem instituída. O grande problema do "universal" se manifesta quando classes menos privilegiadas passam a ter acesso a algumas condições de vida das classes mais altas. Essa ascensão, entretanto, fatalmente tem uma contrapartida negativa: as elites intelectuais apresentam as normas que devem vigorar nos novos tempos usando um discurso abstrato, e aqueles que não têm acesso a esse capital simbólico, ou seja, que não têm acesso à edição dessas normas, são impedidos de se beneficiar das novas circunstâncias ${ }^{43}$.

\section{Considerações Finais}

Neste estudo, foi possível identificar que o desempenho gerencialista presente no Decreto n. 7.508/2011, ao ser interpretado sob a luz do pós-positivismo jurídico, ao invés de ser sinônimo de sucesso do sistema de saúde, expressando a efetividade do direito à saúde via política pública, na realidade, é um fator que provoca o cerceamento do direto à saúde, no que tange especificamente ao tolhimento do acesso aos serviços de saúde de prestação direta.

Esse cerceamento é caracterizado gerencialmente pela incapacidade que a lógica do desempenho gerencialista tem de se coadunar com a lógica da prestação dos serviços públicos de saúde, no que se refere à concretização da integralidade da assistência. Do ponto de vista jurídico, a integralidade da assistência compõe o núcleo essencial do direito à saúde que, ao ser violado, fragiliza o mínimo existencial à garantia da dignidade da pessoa humana como valor a ser assistido.

\footnotetext{
${ }^{42}$ CADEMARTORI, Luiz Henrique Urquhart; GRUBBA, Leilane Serratine. O embasamento dos direitos humanos e sua relação com os direitos fundamentais a partir do diálogo garantista com a teoria da reinvenção dos direitos humanos. Revista de Direito GV, Brasil, v. 8, n. 2, p. 703-724, 2012. Disponível em: <http://www. scielo.br/pdf/rdgv/v8n2/v8n2a13.pdf>. http://dx.doi.org/10.1590/S1808-24322012000200013.

${ }^{43}$ LIMA, Luiz Antonio de Oliveira. O princípio da universalização em Rawls e Habermas: uma avaliação crítica. Revista de Direito GV, v. 7, n. 1, p. 237-258, 2011. Disponível em: <http://www.scielo.br/pdf/rdgv/v7n1/ a12v7n1.pdf>. http://dx.doi.org/10.1590/S1808-24322011000100012.
} 
Na concepção da operacionalização do direito à saúde, como um direito social, a própria noção de "mínimo" já é questionada, por se tratar de um aspecto residual de uma prestação estatal que deve ser entendida como essencial ou básica. Assemelhar o "básico" ou o "essencial" ao "mínimo" já denota o caráter restritivo do direito, que não se deve contentar com a ideia de núcleo essencial como sinônimo de mínimo existencial. Essa sinonímia definitivamente não se aplica ao direito à saúde.

Quando o desempenho gerencialista cerceia o direito ao acesso aos serviços de saúde - o que já é, pelo direito, considerado como "mínimo" existencial -, tende a se tornar algo abaixo do mínimo, um "submínimo" - ou até uma miséria sanitária, tão diminuta que traduz o que há de mais vil no solapamento dos direitos sociais da seguridade, haja vista os vultosos recursos que se acumulam em seu orçamento.

Em síntese, o que a óptica positivista enxerga no desempenho apresentado no Decreto n. 7.508/2011 como letra de lei, que neutraliza a versão gerencialista, dogmatizando-a, a óptica pós-positivista vê o desempenho gerencialista como um véu descortinado para ser lido dentro das circunstâncias sociohistóricas que o encerram, sem, contudo, desconstruir o valor e o princípio que norteiam a concepção essencial do direito à saúde.

Nesse sentido, não há como interpretar e assegurar o direito ao acesso aos serviços de saúde sem considerar os interesses da ordem econômica capitalista, que, com a permissão dos poderes Executivo e Legislativo, adentram a esfera da Administração Pública e fazem novos desenhos da institucionalidade, do modelo de organização, e - em uma visão mais microssociológica - respingam nos processos administrativos do dia a dia dos serviços, por meio de mecanismos sutis de determinação do que o desempenho nesse momento é ou porventura deixará de ser.

\section{Referências}

AITH, Fernando. Curso de direito sanitário: a proteção do direito à saúde no Brasil. São Paulo: Quartier Latin, 2007.

BARCELLOS, Ana Paula de. O direito a prestações de saúde: complexidades, mínimo existencial e o valor das abordagens coletiva e abstrata. Revista da Defensoria Pública, v. 1, n. 1, p. 133-160, jul./dez. 2008. Disponível em: <https://www.defensoria.sp.def.br/dpesp/ repositorio/20/publicacoes/Revista_1_volume_2.pdf $>$.

BERHING, Elaine Rossetti. Política social no capitalismo tardio. 5. ed. São Paulo: Cortez, 2011.

BOTELHO, André. O público e o privado no pensamento social brasileiro. In: BOTELHO, André; SCHWARCZ, Lilia Moritz (Orgs.). Cidadania, um projeto em construção. São Paulo: Claro Enigma, 2012, p. 48-59. 
BRASIL. Ministério da Saúde. PROADESS - Avaliação de Desempenho do Sistema de Saúde brasileiro: indicadores para monitoramento. Relatório final (versão para discussão) Laboratório de Informações em Saúde - LIS Instituto de Comunicação e Informação em Ciência e Tecnologia - ICICT. Fundação Oswaldo Cruz, Rio de Janeiro, 2011.

. Ministério da Saúde. Secretaria de Gestão Estratégica e Participativa. Decreto $n^{o}$ 7.508, de 28 de junho de 2001: regulamentação da Lei no 8.080/90 / Ministério da Saúde. Secretaria de Gestão Estratégica e Participativa. - Brasília: Ministério da Saúde, 2011.(Série E. Legislação de Saúde).

BRAVO, Maria Inês Souza. Considerações finais. In: . Saúde e serviço social no capitalismo: fundamentos sócio-históricos. São Paulo: Cortez, 2013. p. 169-180.

; MATOS, Maurílio Castro de. A saúde no Brasil: reforma sanitária e a ofensiva neoliberal. In: BRAVO, Maria Inês Souza; PEREIRA, Potyara Amazoneida Pereyra. Política social e democracia. São Paulo: Cortez; Rio de Janeiro: UERJ, 2012, p. 200-220.

CADEMARTORI, Luiz Henrique Urquhart; GRUBBA, Leilane Serratine. O embasamento dos direitos humanos e sua relação com os direitos fundamentais a partir do diálogo garantista com a teoria da reinvenção dos direitos humanos. Revista de Direito GV, Brasil, v. 8, n. 2, p. 703-724, 2012. Disponível em: <http://www.scielo.br/pdf/rdgv/v8n2/v8n2a13. pdf>. http://dx.doi.org/10.1590/S1808-24322012000200013.

CASTELO, Rodrigo. O social-liberalismo brasileiro e a miséria ideológica da economia do bem-estar. In: MOTA, Ana Elizabete. (Org.). Desenvolvimentismo e construção de hegemonia: crescimento econômico e reprodução da desigualdade. São Paulo: Cortez, 2012. p. 46-77.

DI PIETRO, Maria Sylvia Zanella. Introdução. In: Parcerias na administração pública: concessão, permissão, franquia, terceirização e outras formas. 4. Edição. São Paulo: Atlas, 2002. p. 15-16.

DONABEDIAN, Avedis. Aspects of medical care administration. Boston: Harvard University Press; 1973.

FIGUEIREDO NETO, Manoel Valente et al. O processo histórico de construção do Sistema Único de Saúde brasileiro e as novas perspectivas. Revista Âmbito Jurídico, v. 5, n. 10, p. 77-81, 2010. Disponível em: <http://www.ambito-juridico.com.br/site/index.php?n_ link=revista_artigos_leitura\&artigo_id=7781>.

KLAZINGA, Niek. Health system performance management: quality for better or for worse. Eurohealth, United Kingdom, v. 16, n. 3, p. 26-28, 2010.

LAURELL, Asa Cristina. Avançando em direção ao passado: a política social no neoliberalismo. In: . Estado e políticas sociais no neoliberalismo. 3. ed. São Paulo: Cortez, 2002. p. 151-178.

LIMA, Luciana Dias. Federalismo, descentralização e regionalização na política de saúde do Brasil. In: ASENSI, Felipe Dutra; PINHEIRO, Roseni (Orgs.). Direito sanitário. Rio de Janeiro: Elsevier. 2012. p. 131-161. 
LIMA, Luiz Antonio de Oliveira. O princípio da universalização em Rawls e Habermas: uma avaliação crítica. Revista de Direito GV, v. 7, n. 1, p. 237-258, 2011. Disponível em: <http://www. scielo.br/pdf/rdgv/v7n1/a12v7n1.pdf>. http://dx.doi.org/10.1590/S1808-24322011000100012.

LOUREIRO, João Carlos. Direito à (proteção da) saúde. Revista da Defensoria Pública, v. 1, n. 1, p. 35-74, jul./dez. 2008. Disponível em: <https://www.defensoria.sp.def.br/dpesp/ repositorio/20/publicacoes/Revista_1_volume_2.pdf $>$.

MARTINIANO, Claudia et al. A luta pela vinculação de recursos para a saúde pública no Brasil a partir do paradigma da universalização. In: DAVI, Jordeana; MARTINIANO, Claudia; PATRIOTA, Lucia Maria. Seguridade social e saúde: desafios e tendências. 2. ed. Campina Grande: Eduepb. 2011. p. 85-116.

MEIRELLES, Dilmária Silva e. O conceito de serviço. Revista de Economia Política, v. 26, n. 1, p. 119-136, 2006. Disponível em: <http://www.scielo.br/pdf/rep/v26n1/a07v26n1. pdf>. http://dx.doi.org/10.1590/S0101-31572006000100007.

MINAYO, Maria Cecilia de Souza. Sobre a complexidade de implementação do SUS: In: SILVA, Silvio Fernandes da (Org). Municipalização da saúde e poder local: sujeitos, atores e políticas. São Paulo: Hucitec, 2001. p. 21-44.

MONTAÑO, Carlos; DURIGUETTO, Maria Lúcia. A (contra)reforma do Estado no Regime de Acumulação Flexível (pós-1973). In: . Estado, classe e movimento social. 3. ed. São Paulo: Cortez, 2011. p. 180-224.

NOGUEIRA, Roberto Passos. O trabalho em serviço de saúde. In: SANTANA, José Paranaguá et al. Desenvolvimento gerencial de unidades básicas do Sistema Único de Saúde (SUS). Brasília: Programa de Desenvolvimento de Recursos Humanos; 1997. p. 183-186.

NYGREN-KRUG, Helena. Saúde e direitos humanos na Organização Mundial da Saúde. Revista de Direitos Humanos e Saúde, v. 1, n. 1, p. 13-18, 2004.

PEREIRA, Potyara Amazoneida Pereira. Do mínimo ao ótimo de satisfação das necessidades mediante o conceito de básicos sociais. In: . Necessidades humanas: subsídios à crítica dos mínimos sociais. 5ª Edição. São Paulo: Cortez, 2008. p. 23-36.

PERONI, Vera Maria Vidal. Políticas sociais em tempos de redefinições do papel do Estado. In: GUIMARÃES, Geny Terezinha Duro; EIDELWEIN, Keren. As políticas sociais brasileiras e as organizações financeiras internacionais. Porto Alegre: Edipucrs, 2010. p. 95-114.

RIOS, Roger Raupp. O direito fundamental à saúde e atividade legislativa. In: ALVES, Sandra Mara Campos; DELDUQUE, Maria Célia; DINO Neto, Nicolao. Direito Sanitário em perspectiva. Brasília: ESMPU: Fiocruz, 2013. v. 2, p. 169-180.

ROMERO, Luiz Carlos. Federalismo e responsabilidade sanitária (percalços da construção de um sistema único de saúde em um estado federado). In: ROMERO, Luiz Carlos; DELDUQUE, Maria Célia. Estudos de direito sanitário: a produção normativa da saúde. Brasília: Senado Federal: Subsecretaria de edições técnicas, 2011. p. 83-98. 
SANTOS, Lenir. Direito a saúde e qualidade de vida - um mundo de corresponsabilidades e fazeres. In: (Org.). Direito da saúde no Brasil. Campinas, SP: Saberes Ed., 2010. p. 15-64.

SANTOS, Nelson Rodrigues. A regulamentação da emenda constitucional n. 29: dificuldades e perspectivas. In: ROMERO, Luiz Carlos; DELDUQUE, Maria Célia. Estudos de direito sanitário: a produção normativa da saúde. Brasília: Senado Federal: Subsecretaria de edições técnicas, 2011. p. 73-82.

SUS, política pública de Estado: seu desenvolvimento instituído e instituinte e a busca de saídas. Ciência \& Saúde Coletiva, v. 18, n. 1, p. 273280, 2013. Disponível em: <http://www.scielo.br/pdf/csc/v18n1/28.pdf>. http://dx.doi.org/10.1590/S1413-81232013000100028.

SARLET, Ingo Wolfgang; FIGUEIREDO, Mariana Filchtiner. Reserva do possível, mínimo existencial e direito à saúde: algumas aproximações. Revista da Defensoria Pública, v. 1, n. 1, p. 179-234, jul./dez. 2008. Disponível em: <https://www.defensoria.sp.def.br/dpesp/ repositorio/20/publicacoes/Revista_1_volume_2.pdf $>$.

SILVA, Maria Magdala Vasconcelos de Araújo. Capitalismo e políticas sociais: o dilema da autonomia dos cidadãos e da defesa da universalidade dos direitos sociais. In: PASTORINI, Alejandra; ALVES, Andrea Moraes; GALIZIA, Silvina Veronica. Estado e cidadania: reflexões sobre as política públicas no Brasil contemporâneo. Rio de Janeiro: Ed. FGV, 2012. p. 17-44.

SIQUEIRA, Márcia Portugal; BUSSINGUER, Elda Coelho de Azevedo. A saúde no Brasil enquanto direito de cidadania: uma dimensão da integralidade regulada. Revista de Direitos e Garantias Fundamentais, v. 8, p. 253-309, 2010. Disponível em: <http://sisbib.fdv.br/index. php/direitosegarantias/article/view/37/35>. http://dx.doi.org/10.18759/rdgf.v0i8.37.

SOUZA, Célia. Instituições e mudanças: reformas da Constituição de 1988, federalismo e políticas públicas. In: HOCHMAN, Gilberto; FARIA, Carlos Alberto Pimenta. Federalismo e políticas públicas no Brasil. Rio de Janeiro: Fiocruz. 2013. p. 91-120.

SPILLER, Eduardo Santiago; SENNA, Ana Maria; SANTOS, José Ferreira dos; VILAR, Josier Marques. Fundamentos da gestão dos serviços de saúde. In: Gestão do serviços de saúde. Rio de Janeiro: Ed. FGV, 2009. p. 19-44.

TORRES, Ricardo Lobo. O direito à saúde, o mínimo existencial e a Defensoria Pública. Revista da Defensoria Pública, v. 1, n. 1, p. 265-278, jul./dez. 2008. Disponível em: <https:// www.defensoria.sp.def.br/dpesp/repositorio/20/publicacoes/Revista_1_volume_2.pdf>.

VANDERPLAAT, Madine. Direitos Humanos: uma perspectiva para a saúde pública. Revista de Direitos Humanos e Saúde, v. 1, n. 1, p. 27-34, 2004.

VIAL, Sanda Regina Martini; OLIVEIRA, Christiano Augusto Seckler. O direito à saúde e os determinantes sociais. Revista da Defensoria Pública, v. 1, n. 1, p. 279-292, jul./dez. 2008. Disponível em: <https://www.defensoria.sp.def.br/dpesp/repositorio/20/publicacoes/ Revista_1_volume_2.pdf $>$. 
WEICHERT, Marlon Alberto. O direito à saúde e o princípio da integralidade. In: SANTOS, Lenir (Org.). Direito da Saúde no Brasil. Campinas, SP: Saberes Ed., 2010. p. 101-142.

Leonardo Carnut - Doutor em Saúde Pública, área de concentração: Política, Gestão e Saúde, pela Faculdade de Saúde Pública da Universidade de São Paulo; especialista em Direito Sanitário pelo Instituto de Direito Sanitário Aplicado. Professor Adjunto. São Paulo/SP, Brasil. E-mail: leonardo.carnut@upe.br.

Jorge Alberto Mamede Masseran - Mestre em Direito pela Universidade Metodista de Piracicaba; especialista em Direito Sanitário pelo Instituto de Direito Sanitário Aplicado. Promotor de Justiça. Piracicaba/SP, Brasil. 